\title{
nature
}

21 January 1999 Volume 397 Issue no 6716

\section{Uncertainty and naivety in Germany's science politics}

The SPD and Green coalition that governs Germany has made notable progress and demonstrated flexibility in the process. But the Greens' lack of expertise needs redressing if good science is to get the support it deserves.

A $\mathrm{n}$ agreement last week within the German coalition government to ban the reprocessing of nuclear waste is a small milestone in German politics — a goal to which the majority of Social Democrats were always committed, but whose attainment was accelerated by their junior coalition partners, the Green party. Should researchers be worried about the impact of Green politics on other technologies and on science?

So far the signs are encouraging. Now nearly 100 days into their first government, the Greens have already shown themselves willing to compromise to stay in power, for example over 'eco-taxes' on power stations and on exempting reactors producing neutrons for research from measures against nuclear energy (see page 189). But they have made clear that their fight against the FRM II research reactor, arrogantly and ill-advisedly designed by the Technical University of Munich to burn weapons-grade, highly enriched uranium, is not over.

German scientists are now nervously waiting to see how the Greens and the Social Democrats will reach a compromise on another sensitive issue: agricultural biotechnology. The Greens tolerate, and the Social Democrats celebrate, biomedical science and its applications, now flourishing in Germany, thanks particularly to former research minister Jürgen Rüttgers.

But the equivocal and hostile attitudes expressed respectively by the Social Democrats and the Greens towards agricultural biotechnology leave plant scientists in a state of uncertainty. One issue is a promised review of how the licensing of field trials of transgenic plants and marketing of transgenic foods are organized. The Greens want this responsibility to be transferred from the Robert Koch Institute, an office of the federal health ministry, to the federal environment ministry. Plant scientists worry that any change in the system, however logical it might seem, could allow the Greens to introduce new restrictions, or at least place licensing in inexperienced hands. The field-trial licensing office in the Robert Koch Institute is rightly respected for its expertise and reliability. At the same time, the sophistication of the Green party in this area is questionable. The change should be resisted.

The second issue is the fate of the newly created plant genome programme GABI, which was launched by Rüttgers last autumn as an attempt to do for agricultural biotechnology what he has already done for medical biotechnology. The scale of the programme has never been defined, and researchers now fear that it could be severely restricted. Serious money would be needed to make GABI competitive with activities in other countries.

The root cause for concern is the fact that the parliamentary Green party has no serious expertise in biotechnology, having ensured that its only expert, former parliamentarian Manuel Kiper, was shunted well down the party list before last September's elections. Since the party has a strong, and negative, political stance on agricultural applications of biotechnology, it needs to fill this regrettable gap as fast as possible. It must recognize that GABI will deliver important basic research. The Greens' ability to compromise is welcome, but given its influence, its scientific and technical naivety is unacceptable.

\section{Arima ascendant}

The choice of the new head of Japan's education ministry and Science and Technology Agency is to be applauded.

The decision of Japan's prime minister Keizo Obuchi to retain Akito Arima, a physicist and former president of Tokyo Univer-

sity, as minister of education and also appoint him as head of the Science and Technology Agency in his new coalition government (see page 188) is a wise move that should help smooth the complex impending merger of the agency and the ministry.

Arima, a champion of reform of Japan's public-sector research system with experience of working with both the education ministry and the agency in his former roles as president of Tokyo University and head of the agency's Institute of Physical and Chemical Research (RIKEN), is ideally qualified for the job. He is also rare among Japan's scientists in having the political savvy and determination to carry out his difficult task.

The merger of the education ministry and agency scheduled for 2001 will not be easy. The organizations are as alike as oil and water and have often clashed in the past. The education ministry is large, conservative and devoted primarily to issues of education in schools and universities rather than scientific research. The much smaller and younger Science and Technology Agency is a comparatively lightweight organization in the political world that has devoted most of its resources to large-scale science and technology projects in space, marine science and nuclear energy.

One area where rapid progress can be expected under Arima will be the introduction of a much-needed nationwide system for assessing research in universities, as well in institutes of the agency. Arima has been a pioneer of such assessment in his former roles at Tokyo University and RIKEN. He is also a strong advocate of building greater public awareness and understanding of science and of more creative science curricula in schools. All of which is heartily to be welcomed.

A delicate task for Arima will be rationalization of overlapping functions of the agency and ministry, particularly in the areas of marine and space science. While a case might be made for greater sharing of resources between the agency's Japan Marine Science and Technology Center and the Ocean Research Institute of Tokyo University, there is greater need for caution with space science, where the internationally renowned Institute of Space and Astronautical Science under the ministry of education could be seriously impaired by any attempt to merge it with the agency's huge National Space Development Agency, which is run by engineers. Arima must retain the best interests of science in dealing with these complex issues. 